\title{
ARTICLE
}

\section{Sensory impairment and intellectual disability $^{\dagger}$}

\author{
Reza Kiani \& Helen Miller
}

Reza Kiani is a consultant in learning disability in The Agnes Unit of Leicester Frith Hospital. His specialist research area is in the field of autism and mental ill health in people with intellectual disability and sensory impairment. Helen Miller is a consultant psychiatrist with the National Deaf Services, South West London and St George's Mental Health NHS Trust, where she is providing mental health services for adults with hearing loss and deaf-blindness.

Correspondence Reza Kiani, Leicestershire Partnership NHS Trust, Learning Disability Services, Mansion House, Frith Hospital, Leicester LE3 90F, UK. Email: reza. kiani@leicspart.nhs.uk

${ }^{\dagger}$ A shorter and illustrated version of this article is published by the Royal College of Psychiatrists as an online CPD module (www.psychiatrycpd. co.uk/learningmodules/ sensoryimpairmentandintelle.aspx).

\begin{abstract}
SUMMARY
Sensory (visual and hearing) impairment has significant detrimental impact on sociocognitive and language development. Despite this, it is very much underrecognised and underdiagnosed in people with intellectual disability. Raising awareness of sensory impairment among professionals and carers is extremely important for early management to prevent further social handicap in people with intellectual disability. This article reviews sensory impairment in intellectual disability and its association with autism-spectrum disorder and mental illness.
\end{abstract}

\section{DECLARATION OF INTEREST}

None.

The prevalence of sensory impairment (visual and hearing) is much greater in adults with intellectual disability than in the general population. Difficulty in accessing generic services and the deficits in language and communication skills found in this population make the assessment of sensory impairment a challenge. In practice, diagnostic overshadowing can occur, with changes in behaviour attributed to the intellectual disability or to mental illness rather than to sensory impairment. Thus, the individual may receive inappropriate treatment that does not address the underlying problem.

Our purpose here is to raise awareness among healthcare professionals, enabling early detection and management of sensory impairment in people with intellectual disability.

\section{Hearing impairment}

Profound congenital hearing loss (Box 1) is seen in at least 1 in 1000 people in the general population. The degree of hearing impairment can be classified by audiometry (Table 1), which measures the intensity of a sound (in decibels, $\mathrm{dB}$ ) required for someone to hear at a particular frequency (in Hertz, Hz). A person with normal hearing ability can hear sounds as low as $0-20 \mathrm{~dB}$ (a whisper is about $10-20 \mathrm{~dB}$ ). A hearing impairment is defined as an average hearing loss in the best ear of $25 \mathrm{~dB}$ or more at 1, 2 and $4 \mathrm{kHz}$ (Evenhuis 2001).

\section{BOX 1 Terminology}

The literature on Deaf culture and British Sign Language commonly uses 'Deaf' with a capital 'D' to differentiate congenital hearing loss (Deafness) from 'deaf', meaning late-onset or acquired hearing impairment (deafness).

In the UK, people who are Deaf tend to use British Sign Language as their first language and identify themselves as culturally Deaf. People who are deaf, on the other hand, often regard their hearing loss as something that can be treated, choose not to associate with the Deaf community and use oral communication.

In this article, we use the clinical terms 'congenital hearing loss' and 'acquired hearing impairment'.

The prevalence of hearing impairment is at least 40 times higher in people with intellectual disability compared with the general population (Carvill 2001). In addition to developing conductive/ sensorineural hearing loss, people with intellectual disability may also have central (cortical) auditory processing problems.

\section{Visual impairment}

Normal visual acuity is scored as 1 . According to the World Health Organization, a corrected visual acuity for the best eye of $<0.3$ or a visual field of below $30^{\circ}$ (normal visual field is $180^{\circ}$ ) are indicators of visual impairment, and blindness is defined as a visual acuity of $<0.05$ or a visual field of $<10^{\circ}$ (van den Broek 2006). The prevalence of visual impairment is approximately $0.5-2 \%$ in the general population but is at least 8.5 times higher in people with intellectual disability (Warburg 2001).

\section{TABLE 1 Degree of hearing impairment based on audiography}

\begin{tabular}{|ll|}
\hline $\begin{array}{l}\text { Degree of hearing } \\
\text { impairment }\end{array}$ & Hearing loss, dB \\
\hline Mild & $20-39$ \\
\hline Moderate & $40-69$ \\
\hline Severe & $\begin{array}{l}70-94 \text { (difficulty even with a } \\
\text { hearing aid) }\end{array}$ \\
\hline Profound & $>95$ (no perception) \\
\hline
\end{tabular}




\section{Comorbidity of visual and hearing impairment}

At least half of children born blind have additional disabilities, including hearing impairment, epilepsy, motor difficulties and intellectual disability. Those with congenital hearing loss also have a high incidence of comorbid visual impairment.

The prevalence of deaf-blindness (severely impaired hearing and vision) is about 1 in 10000 school-age children in the UK. The aetiology includes extreme prematurity, congenital rubella syndrome, meningoencephalitis and Usher syndrome. Many individuals with congenital deaf-blindness have some degree of intellectual disability.

\section{Factors influencing the prevalence of sensory impairment}

\section{Severity of intellectual disability}

A study in a typical Dutch care organisation found that $92 \%$ of people with severe and profound intellectual disability had visual impairment, with nearly two-thirds of cases going unnoticed by carers (van den Broek 2006).

\section{Age}

As in the general population, the prevalence of sensory impairment increases with age in people with intellectual disability (Janicki 1998).

\section{Sociodemographic factors}

Congenital hearing loss may be more common among the immigrant population due to marriage within a close family network, a greater chance of poverty and inadequate access to healthcare and immunisation (Royal National Institute for Deaf People 2003). A recent study found a strong association between poverty and an increased prevalence of blindness (Gilbert 2008).

\section{Aetiology of sensory impairment}

A number of conditions can cause both intellectual disability and sensory impairment (Table 2). At least $50 \%$ of cases of congenital hearing loss are caused by genetic disorders, which are primarily a result of inheriting recessive genes (e.g. gene GJB2 for connexin 26 protein).

An interesting mutation of the mitochondrial DNA (m.1555A $>$ G), which is exclusively inherited maternally, is known to predispose a person to vestibular and ototoxic effects of even therapeutic doses of aminoglycosides. The association is so strong that it has been suggested that everyone who is going to have multiple courses of aminoglycosides should be screened for this mutation to detect the vulnerability to hearing loss (BitnerGlindzicz 2007).

\section{Sensory impairment and different syndromes}

\section{Down syndrome}

Structural anomalies of sensory organs (e.g. narrow ear canals, keratoconus) are common in people with Down syndrome. As a result, sensory impairments may occur several decades earlier in people with Down syndrome than in the general population.

\section{Usher syndrome}

Usher syndrome is the most common cause of deaf-blindness in adults, causing $5-10 \%$ of cases of congenital hearing loss, $18 \%$ of cases of retinitis pigmentosa and over $50 \%$ of cases of deaf-blindness. The prevalence in the general population is $3-5$ per 100000 (Rosenburg 1997). Usher syndrome causes gradual loss of vision due to progressive retinitis pigmentosa. Retinitis pigmentosa, which is essential for diagnosis, can be confirmed by electroretinography. Visual impairment usually starts with night blindness during adolescence that progresses to tunnel vision and blindness. Usher syndrome may also cause problems with balance. Hallgren (1959) reported an association between Usher syndrome and psychosis in up to $23 \%$ of patients. Most of the patients had intellectual disability.

\section{Congenital rubella syndrome}

Rubella can cause sensorineural congenital hearing loss, central auditory imperceptions, visual impairment and developmental delay, all of which

TABLE 2 Genetic syndromes associated with sensory impairment

\begin{tabular}{|ll|}
\hline Genetic syndrome & Signs and symptoms \\
\hline Alport syndrome & Kidney abnormalities \\
\hline CHARGE & Coloboma, heart defects, atresia choanae, ear anomalies \\
\hline Coffin-Lowry syndrome & Short, tapered fingers and hypertelorism \\
\hline $\begin{array}{l}\text { Jervell and Lange-Nielson } \\
\text { syndrome }\end{array}$ & Fainting and long QT interval in electrocardiogram \\
\hline Klippel-Feil syndrome & Short webbed neck \\
\hline MELAS & Myopathy, encephalitis, lactic acidosis and stroke \\
\hline Neurofibromatosis & Café au lait spots \\
\hline Pendred syndrome & Hypothyroidism \\
\hline Stickler syndrome & Joint hyperflexibility, cataract, glaucoma and retinal detachment \\
\hline Treacher Collins syndrome & Facial dysmorphology and coloboma \\
\hline Usher syndrome & Retinitis pigmentosa \\
\hline Waardenburg syndrome & Blue iris and white forelock \\
\hline
\end{tabular}


may be underdiagnosed in people with intellectual disability. A longitudinal study of 243 preschool children with congenital rubella syndrome found that 37\% had intellectual disability, 15\% had reactive behaviour disorder and $7 \%$ had autism at base line (Chess 1971). When followed up at the age of 8-9 years, the prevalence of intellectual disability had decreased to 25\%; however, behavioural problems had increased because of neurological damage studied (Chess 1977). The author also reported three new cases of autism and two remissions at follow-up, and hypothesised that the course of autism was that of a chronic infection, with remission and delayed emergence of symptoms.

There is an increased prevalence of psychosis in people who have congenital hearing loss through rubella. A follow-up study in young adults of a birth cohort who experienced in utero exposure to rubella in the 1964 rubella epidemic found a fivefold increase in non-affective psychosis (Brown 2000).

\section{Sensory impairment, psychological development and autism}

Language (spoken or sign) has a protective effect on psychosocial development. Children with congenital hearing loss who are born to families with congenital hearing loss and exposed to signing early in life enjoy normal cognitive development (Austen 2007).

In infants with a pre-lingual sensory deficit, there is a lack of incidental learning about the world (e.g. overhearing conversations and seeing other people's body language). This has a huge impact on their cognitive, psychosocial and language development, to the extent that it can affect the development of theory of mind and produce a picture very similar to autism (Hoevenaars-van den Boom 2009). The presence of an existing intellectual disability is thought to exacerbate this effect (Peterson 2000).

Hearing impairment and autism are both disorders of communication. Children diagnosed with autism are often initially thought by their parents to have congenital hearing loss (Grewe 1994). Both conditions can co-occur. Rosenhall et al (1999) found that $9.5 \%$ of children with autism had hearing impairment. In a sample of children with hearing impairment, Jure and colleagues (1991) reported a prevalence of autism of $4 \%$ and found a relationship between the degree of intellectual disability (not degree of congenital hearing loss) and autism.

Several studies have shown an association between congenital blindness, autism and autismlike symptoms. In a study of 102 infants with
BOX 2 Challenges in studying the association of autism with sensory impairment

- Heterogeneity of people with sensory impairment (e.g. different degrees of blindness or hearing loss)

- Heterogeneity of people with autism-spectrum disorder

- Achieving sufficient sample size

- Finding an appropriate control group

- Presence of additional disabilities (e.g. brain damage)

- Lack of valid assessment tools

profound congenital blindness, Cass et al (1994) found that $31 \%$ manifested a developmental setback at 15-27 months, which was related to the severity of the visual impairment.

Studies looking at the effect of congenital blindness on sociocognitive development divide children into two categories based on the presence or absence of 'form vision', defined as awareness of visual objects that do not reflect light (Dale 2005). Congenital visual disorders can also be classified according to the site of abnormality: cerebral, if the brain and posterior visual pathway are involved; or peripheral, if the globe, retina or anterior visual pathways are affected.

Box 2 details the challenges of studying the association of autism with sensory impairment.

\section{Sensory impairment and mental illness}

In old age, acquired hearing impairment is known to be associated with psychotic illness (du Feu 2003) and acquired blindness with visual hallucinations (Charles Bonnet syndrome).

In the general population, there is an excess of behavioural and emotional difficulties in people with congenital hearing loss (van Gent 2007); however, this association seems to be consequent to difficulties in communication and the stigma and discrimination experienced in general, rather than any other specific association.

In people with intellectual disability and sensory impairment, studies have indicated an association between the sensory impairment and challenging and self-injurious behaviours (Carvill 2002).

\section{Assessment}

People with intellectual disability may not be able to report visual or hearing problems because of difficulties with language and communication. As a result, changes in hearing or vision may present as changes in behaviour. Carers may perceive a person to be non-cooperative when in reality they cannot hear or see properly. Some people try to cover up 
BOX 3 Examples of carers' comments about an unrecognised sensory impairment

- He has taken to ignoring us

- He can talk so he is not deaf

- He can hear/see when he wants to

- He understands what we say

- She keeps breaking things

- She hits me with her white stick and won't use it anymore

- She won't go out

- We put the fluorescent light on in the kitchen, then she starts breaking things

- She sees more than you think

their sensory loss and this can be misinterpreted by carers, leading to statements such as 'he can hear/see when he wants to' (Box 3).

Training carers and staff can help them to identify sensory impairments, which can then be followed up by specialist assessment (Fellinger 2009). Specialist assessment can help service users and carers to be clear about what an individual can and cannot see or hear, and ensures that they have access to appropriate aids and services. However, research shows that $39 \%$ of people with intellectual disability receive less eye care than those in the general population (Starling 2006). Research also shows that $30 \%$ of people with intellectual disability and hearing impairment have never had their hearing tested (Timehin 2004).

\section{Assessment methods}

People with intellectual disability should be regularly screened for sensory impairment. Health guidelines published by the International Association for the Scientific Study of Intellectual Disabilities (2002) recommend that specialist screening for age-related visual and hearing loss in people with intellectual disability should be started at the age of 45 and repeated every 5 years thereafter. People with Down syndrome should also have a one-off visual screening at the age of 30 years and their hearing should be monitored more frequently (i.e. at 3-year intervals).

Completing a functional visual or hearing checklist (Boxes 4 and 5), taking a history (Box 6) and conducting a physical examination are good starting points for assessment. The involvement of a speech and language therapist early on in the assessment process is invaluable, as is the development of a unique communication passport for the individual concerned. A communication passport provides important information about a

BOX 4 Assessment of visual impairment

\begin{tabular}{lll}
\hline $\begin{array}{ll}\text { Visual impairment checklist } \\
\text { - External appearance of }\end{array}$ & - Eye poking & - Not looking confident \\
the eyes (e.g. coloboma, & - Bringing objects very & when walking \\
squint) & - Not recognising familiar & - Visual acuity tests \\
- Abnormal eye movements & faces & - Visual field tests \\
- Watching from angle of & - Groping to find things & - Ophthalmoscopy \\
eyes & - Preference for bright & - Contrast sensitivity tests \\
- Head tilting & objects & - Binocular vision tests \\
- Finger flicking in front of & - Bumping into things & \\
the eyes & - Difficulty using steps &
\end{tabular}

service user's ways of communication and how best others can communicate with them.

If a patient needs to undergo specialist assessment, preparatory work should be undertaken using video materials, role-play and illustrated information leaflets. Ideally, assessment should be carried out in specialist sensory services, as generic services may be unable to address the person's specific needs.

It is important to note that stereotypical movements (e.g. flicking fingers) and fascination with or avoidance of certain stimuli (sensory seeking and avoiding behaviours) have been commonly described in people with autism. Care should be taken not to confuse these with the symptoms of visual or hearing loss when assessing individuals with autism.

\section{Management strategies}

Effective management in people with intellectual disability is difficult since medical treatments form

\section{BOX 5 Assessment of hearing impairment}

Functional hearing checklist

- Size and shape of the ears (absent or very small ears)

- Talking unusually loudly or in a whisper

- Not taking notice of prolonged or loud noises (e.g. fire alarms)

- Startled by people approaching who are not in sight

- Prefers television/radio to be on louder than normal

- Responding only to certain voices (inconsistent in response)

- Misunderstanding instructions

- Covering, poking, slapping ears
- Experimenting with noises

- Moving close to sounds

Specialist assessment

- Otoscopy

- Pure tone audiometry

- Warble tone audiometry

- McCormick Toy Discrimination Test (Yeates 2000)

- South London Object Test (Yeates 2000)

- Tympanometry

- Otoacoustic emission

- Brainstem evoked response 
B0X 6 Points to consider when taking a history to assess sensory impairment

- Family history of sensory deficits and genetic disorders

- History of kernicterus, perinatal asphyxia and in utero exposure to TORCHES (toxoplasmosis, rubella, cytomegalovirus, herpes simplex, syphilis)

- Childhood history of meningoencephalitis

- Developmental milestones

- Any recent change in behaviour

- Previous injury to ears/eyes

- Discharge, itchiness and pain in sensory organs

- Problems with ear wax

- Dizziness, vertigo, loss of balance and tinnitus

- Double vision or blurred vision

- Previous assessments and provision of hearing aids or glasses

- Past operations on sensory organs

- Past or current use of medication affecting sensory organs (e.g. aminoglycosides)

- Motor abnormalities

only one component of the management strategy (Box 7). It requires an approach that is not simply multimodal and multidisciplinary, but also multiagency combining education, Social Services and other agencies such as charities to ensure a holistic response to the individual's difficulties. Intensive long-term intervention with different components is the best strategy to address patients' complex

\section{BOX 7 Management strategies for sensory impairment and intellectual} disability

\begin{tabular}{ll}
\hline Medical & Communication \\
- Medication & - Picture Exchange Communication System \\
- Glasses & (PECS) \\
- Hearing aids & - Braille and Moon \\
- Surgery & - Sign language and Makaton \\
Environmental & - Deaf-blind manual and block alphabet \\
- Appropriate lighting and contrast colouring & - Objects of reference and calendar boxes \\
- Consistency of rooms & Others \\
- A hearing loop system & - Treatment and Education of Autistic and \\
- Light or vibrating alarms and clocks & related Communication handicapped \\
- Pager for doorbells & Children (TEACCH) \\
- Use of special carpeting and audio, touch & - Sensory integration \\
and smell orientation & - Irlen tinted glasses (for scotopic sensitivity \\
- Good signage, big calendar and clock, use & or Irlen syndrome) \\
of magnifying lenses & - Applied behavioural analysis \\
& - Intensive interaction \\
\end{tabular}

needs. Training the carer and staff to be aware of hearing and sight impairment is a key component to ensure successful long-term management.

\section{Medical management}

People with intellectual disability are able to express their wishes and ideas regarding hearing aids, provided that they are given sufficient information (Meuwese-Jongejeugd 2007). However, research shows that, despite the positive effect of hearing aids on communication and behaviour, only $24 \%$ of people with intellectual disability have ongoing assessments and hearing-aid maintenance. Moreover, few carers and staff receive training on maintaining hearing aids (Timehin 2004).

Box 8 shows some reasons why individuals may be reluctant to wear hearing aids and glasses and potential remedies (Acker 2004).

\section{Communication methods}

Communication with people with intellectual disability who have sensory impairment is challenging and complex. Staff working in such settings must receive regular training and be given the opportunity to practise, to enable them to communicate effectively with service users (Box 9).

Most people with intellectual disability with congenital hearing loss use a very simple version of sign language. Some might know Makaton

BOX 8 Reluctance to use hearing aids or glasses: problems and solutions

Problems

- Badly fitting or painful device

- Broken or lost device

- Poorly maintained device

- Ineffectual device owing to wrong assessment or diagnosis

- Feeling stigmatised

- Teasing by others

Solutions

- Allow individuals to choose their preferred model and colour

- Gradually extend usage from one setting to another

- Give the individual the responsibility for using and cleaning the device

- Positive reinforcement and lots of praise

- Integrate devices into everyday life

- Establish a routine around the device

- Practise role-play and modelling 
or Signalong, which have basic sign language vocabulary and structure. The Picture Exchange Communication System (PECS) can also be used to facilitate service users' autonomy by showing pictures of the items they need. For people who are blind, communication can be via Braille, Moon or audio materials. For those who are congenitally deaf-blind, it is essential to communicate through the deaf-blind manual, hands-on signing, visual frame signing or block alphabet (information on these can be found on the websites listed in Box 10).

\section{Environmental adaptations}

A person with dual sensory loss experiences a greater degree of impairment than the sum of the visual and hearing impairment alone. Dual sensory loss is a major risk factor for falls and injuries, therefore the environment should be adapted to enable affected individuals to orient themselves through touch and smell. For those with a diagnosis of autism, the environment must be autism friendly, so that it appears less distracting and at the same time safe, uncluttered and easy to use. Each room should serve a clear function and unnecessary noises should be eliminated. The use of the remaining eyesight should be encouraged by reducing glare and using appropriate lighting and contrasting colours. An occupational therapist or charity organisation (Box 10) could be consulted for the environmental adaptation of a day-care centre or the home (Butler 2004).

\section{Psychosocial intervention}

Psychological approaches (e.g. psychoeducation) tailored to the individual's level of language and cognitive ability are important to help them make sense of the social world around them. This can be complemented with social skills training (e.g. social stories) to improve their understanding of other people's emotions and mind as well as their own.

\section{Sensory integration and intensive interaction}

A study (Kern 2007) on sensory processing in autism has shown that there are global abnormalities in the five main sensory modalities (tactile, gustatory, olfactory, visual and auditory) and that these seem to be interrelated. Some biographical accounts of people with autism show that sensory integration might be beneficial, helping them to use more than one sense at a time. For some people with severe autism and intellectual disability, intensive interaction has also been helpful in establishing attention and emotional engagement (Caldwell 2008).
BOX 9 Communicating with people with sensory impairment

\begin{tabular}{|c|c|}
\hline Do: & Don't: \\
\hline $\begin{array}{l}\text { - always tell them where you are/where } \\
\text { you are going to go }\end{array}$ & $\begin{array}{l}\text { - assume the person is totally blind and } \\
\text { deaf: they may have some residual visual }\end{array}$ \\
\hline consider supplementing verbal & or hearing ability \\
\hline $\begin{array}{l}\text { communication with simultaneous signs } \\
\text { and symbols }\end{array}$ & $\begin{array}{l}\text { - shout or speak very loudly unless you are } \\
\text { asked to do so }\end{array}$ \\
\hline $\begin{array}{l}\text { - facilitate lip reading by allowing them to } \\
\text { see your mouth clearly }\end{array}$ & $\begin{array}{l}\text { - misinterpret head tilt for extrapyramidal } \\
\text { symptoms: they may be using their better }\end{array}$ \\
\hline encourage those with macular & ar to listen to you \\
\hline $\begin{array}{l}\text { degeneration to look at objects through } \\
\text { the angle of their eyes and teach them to } \\
\text { use magnifying lenses }\end{array}$ & $\begin{array}{l}\text { - assume the patient lacks eye contact (e.g. } \\
\text { as in autism and fragile-X syndrome) when } \\
\text { they may be looking slightly off-axis owing }\end{array}$ \\
\hline $\begin{array}{l}\text { respect confidentiality by not talking too } \\
\text { loudly }\end{array}$ & e loss of central vision \\
\hline
\end{tabular}

\section{Other strategies}

Treatment and Education of Autistic and related Communication handicapped CHildren (TEACCH) can reduce anxiety by providing a structured and predictable daily timetable for activities. Both TEACCH and PECS can be adapted for people with visual impairment by replacing pictures with objects of reference. Objects of reference are taught by pairing an event with an object, for example handing a cup to a person with deaf-blindness when it is time for a drink.

\section{Service provision}

There are few specialist services or care homes in the UK with expertise in dealing with people with intellectual disability who also have autism and profound sensory impairment. Each person will therefore require a care package tailored to their individual needs. In practice, a transdisciplinary model can be used (Pring 2005), whereby the individual is placed in a setting where there is an expertise in one area (e.g. autism) to which additional support and training in another area (e.g. sensory impairment) can be added.

\section{BOX 10 Charities for people with sensory impairment}

Look Up (www.lookupinfo.org)

SeeAbility (www.seeability.org)

Deafblind UK (www.deafblind.org)

Vista (www.vistablind.org.uk)

Sense (www.sense.org.uk)

Royal National Institute of Blind People (www.rnib.org.uk)

Royal National Institute for Deaf People (www.rnid.org.uk) 


\section{MCO answers}

$\begin{array}{lllll}1 \mathrm{e} & 2 \mathrm{~b} & 3 \mathrm{a} & 4 \mathrm{~d} & 5 \mathrm{c}\end{array}$

\section{Conclusions}

The provision of effective healthcare for people with intellectual disability who also have sensory impairment is a continuing challenge for intellectual disability services. Most professionals lack confidence in the assessment and management of mental illness or autism-spectrum disorder in this population. Resources are sparse and there are limited numbers of specialist services to address this group's needs. Ideally, a sensory impairment team, care pathway and clinical network should be developed within every intellectual disability service to work across the professional and organisational boundaries and in close collaboration with audiology and ophthalmology services. Although challenging, this would be greatly beneficial for our patients and rewarding for the dedicated professionals who work with them.

\section{Acknowledgements}

We are grateful to Maureen Richardson and Alison Bennett, speech and language therapists at Leicester Frith Hospital, for providing useful information on assessment and management of sensory impairment in people with intellectual disability. We also thank Dr Mary Barrett, Wendy Pell and Kevin De-Voy for their help with the manuscript.

\section{References}

A full reference list is available as an online supplement.

Acker T, Crocker S (2004) Tip-toeing through technology. In Deafness in Mind: Working Psychologically with Deaf People Across the Life Span (eds S Austen, S Crocker): 53-72. Whurr.

Austen S, Jeffery D (eds) (2007) Deafness and Challenging Behaviour: The $360^{\circ}$ Perspective. John Wiley \& Sons.

Bitner-Glindzicz M, Rahman S (2007) Ototoxicity caused by aminoglycosides is severe and permanent in genetically susceptible people. BMJ 335: 784-5.

Brown AS, Cohen P, Greenwald S, et al (2000) Non-affective psychosis after prenatal exposure to rubella. American Journal of Psychiatry 157: 438-43.

Butler S (ed) (2004) Hearing and Sight Loss: A Handbook for Professional Carers. Age Concern.

Caldwell P. Horwood J (eds) (2008) Using Intensive Interaction and Sensory Integration: A Handbook for Those Who Support People with Severe Autistic Spectrum Disorder. Jessica Kingsley Publishers.

Carvill S (2001) Sensory impairment, intellectual disability and psychiatry. Journal of Intellectual Disability Research 45: 467-83.

Carvill S, Marston G (2002) People with intellectual disability, sensory impairments and behavioural disorder: a case series. Journal of Intellectual Disability Research 46: 264-72.

Cass H, Sonksen PM, McConachie HR (1994) Developmental set back in severe visual impairment. Archives of Disease in Childhood 70: 192-6.

Chess S (1971) Autism in children with congenital rubella. Journal of Autism and Childhood Schizophrenia 1: 33-47.

Chess $S$ (1977) Follow up report on autism in congenital rubella. Journal of Autism and Childhood Schizophrenia 7: 69-81.

Dale N (2005) Early signs of developmental setback and autism in infants with severe visual impairment. In Autism and Blindness: Research and Reflections (ed L Pring): 74-98. Whurr du Feu M, Fergusson K (2003) Sensory impairment and mental health. Advances in Psychiatric Treatment 9: 95-103.

Evenhuis HM, Theunissen M, Denkers I, et al (2001) Prevalence of visual and hearing impairment in a Dutch institutionalised population with intellectual disability. Journal of Intellectual Disability Research 45: 457-64

Fellinger J, Holzinger D, Dirmhirn A, et al (2009) Failure to detect deafblindness in a population of people with intellectual disability. Journal of Intellectual Disability Research 53: 874-81.

Gilbert CE, Shah SP, Jadoon MZ, et al (2008) Poverty and blindness in Pakistan: results from the Pakistan national blindness and visual impairment survey. BMJ 336: 29-32.

Grewe TS, Danhauer JL, Danhauer KJ, et al (1994) Clinical use of otoacoustic emissions in children with autism. International Journal of Pediatric Otorhinolaryngology 30: 123-32.

Hallgren B (1959) Retinitis pigmentosa combined with congenital deafness, with vestibule-cerebellar ataxia and mental abnormality in a proportion of cases. A clinical and genetic-statistical study. Acta Psychiatrica Scandinavica 138: 5-101.

Hoevenaars-van den Boom MAA, Antonissen ACFM, Knoors $\mathrm{H}$, et al (2009) Differentiating characteristics of deafblindness and autism in people with congenital deafblindness and profound intellectual disability. Journal of Intellectual Disability Research 53: 548-58.

International Association for the Scientific Study of Intellectual Disabilities (2002) Health Guidelines for Adults with an Intellectual Disability. IASSID (http://www.iassid.org/pdf/healthguidelines-2002.pdf).

Janicki MP, Dalton AM (1998) Sensory impairments among older adults with intellectual disability. Journal of Intellectual and Developmental Disability 23: 3-11.

Jure R, Rapin I, Tuchman RF (1991) Hearing-impaired autistic children. Developmental Medicine and Child Neurology 33: 1062-72.

Kern JK, Trivedi MH, Grannemann BD, et al (2007) Sensory correlations in autism. Autism 11: 123-34.

Meuwese-Jongejeugd A, Verschuure H, Evenhuis HM (2007) Hearing aids: expectations and satisfaction of people with an intellectual disability, a descriptive pilot study. Journal of Intellectual Disability Research 51: 913-22.

Peterson CC, Siegal M (2000) Insights into theory of mind from deafness and autism. Mind and Language 15: 123-45.

Pring L (ed) (2005) Autism and Blindness: Research and Reflection. Whurr. Rosenburg T, Haim M, Hauch AM, et al (1997) The prevalence of Usher syndrome and other retinal dystrophy hearing impairment associations. Clinical Genetics 51: 314-21.

Rosenhall U, Nordin V, Sandstrom M, et al (1999) Autism and hearing loss. Journal of Autism and Developmental Disorders 29: 349-57.

Royal National Institute for Deaf people (2003) Facts and Figures on Deafness and Tinnitus (Factsheet). RNID (www.rnid.org.uk).

Starling S, Willis A, Dracup M, et al (2006) Right to sight. Journal of Intellectual Disabilities 10: 337-55.

Timehin C, Timehin E (2004) Prevalence of hearing impairment in a community population of adults with learning disability: access to audiology and impact on behaviour. British Journal of Learning Disabilities 32: $128-32$.

van den Broek EGC, Janssen CGC, van Ramshorst T, et al (2006) Visual impairment in people with severe and profound multiple disability: an inventory of visual functioning. Journal of Intellectual Disability Research 50: 470-5

van Gent T, Goedhart AW, Hindley PA, et al (2007) Prevalence and correlates of psychopathology in a sample of deaf adolescents. Journal of Child Psychology and Psychiatry 48: 950-8.

Warburg M (2001) Visual impairment in adult people with intellectual disability: literature review. Journal of Intellectual Disability Research 45: 424-38.

Yeates S (2000) Audiological assessment of people with special difficulties. In Mental Health and Deafness (eds P Hindley, N Kitson): 25-41. Whurr 
MCQs

Select the single best option for each question stem

1 Regarding congenital deaf-blindness:

$a$ it has a higher prevalence in the general population than in people with intellectual disability

b it is not caused by congenital rubella syndrome

c extreme prematurity is one of the rarer causes

d Usher syndrome is one cause

e most individuals will have an $10<70$.

\section{A higher incidence of sensory impairment} is shown in studies:

a of younger populations

b of ethnic minorities

c of people with $10>70$

$\mathrm{d}$ conducted in the community (as compared with those conducted on in-patients)

e of people with borderline intellectual functioning.
3 Regarding assessment of sensory impairment in people with intellectual disability:

a it should ideally be sought from a specialist service

b most individuals receive a better service than the general population

c assessment by a speech and language therapist is usually unnecessary

$\mathrm{d}$ involvement of an occupational therapist is usually unnecessary

$\mathrm{e}$ it is usually enough to rely on a carer's account.

4 Which of the following statements is true?

a there is no increased rate of autism with congenital hearing loss

b autism is very rare in congenital rubella syndrome

c autistic symptoms are rare in congenital blindness $d$ there is an increased risk of psychosis in people with congenital rubella syndrome

e congenital blindness is not associated with delayed development of theory of mind.

5 Regarding the management of sensory impairment in people with intellectual disability:

a medical treatment is the main component of any effective strategy

b environmental adaptation has no significant role

c one essential component of a management strategy is to train carers to be aware of sensory impairment

$\mathrm{d}$ the TEACCH programme cannot be adapted for those with autism and blindness

e PECS cannot be adapted for those with autism and blindness. 